\title{
Optimizing Gear Shifting Strategy for Off-Road Vehicle with Dynamic Programming
}

\author{
Xinxin Zhao, ${ }^{1,2}$ Wenming Zhang, ${ }^{1}$ Yali Feng, ${ }^{1}$ and Yaodong Yang ${ }^{1}$ \\ ${ }^{1}$ School of Mechanical Engineering, University of Science and Technology Beijing, Beijing 100083, China \\ ${ }^{2}$ Department of System Design Engineering, University of Waterloo, Waterloo, ON, Canada N2L 3G1 \\ Correspondence should be addressed to Yali Feng; ylfeng126@126.com
}

Received 4 April 2014; Revised 28 May 2014; Accepted 6 June 2014; Published 22 June 2014

Academic Editor: Hamid Reza Karimi

Copyright (C) 2014 Xinxin Zhao et al. This is an open access article distributed under the Creative Commons Attribution License, which permits unrestricted use, distribution, and reproduction in any medium, provided the original work is properly cited.

\begin{abstract}
Gear shifting strategy of vehicle is important aid for the acquisition of dynamic performance and high economy. A dynamic programming (DP) algorithm is used to optimize the gear shifting schedule for off-road vehicle by using an objective function that weighs fuel use and trip time. The optimization is accomplished through discrete dynamic programming and a trade-off between trip time and fuel consumption is analyzed. By using concave and convex surface road as road profile, an optimal gear shifting strategy is used to control the longitudinal behavior of the vehicle. Simulation results show that the trip time can be reduced by powerful gear shifting strategy and fuel consumption can achieve high economy with economical gear shifting strategy in different initial conditions and route cases.
\end{abstract}

\section{Instruction}

The notable differences between off-road vehicle and passenger car include special functions, huge weight capacity, and rough driving area, which may lead to gear shifting frequently. The automatic transmission had been installed in construction vehicle since the mid of last century. Mining trucks with mechanical powertrain system often equip automatic transmissions, which could enhance the production efficiency. To achieve high economy, gear shifting strategy of automatic transmission is a challenging problem for researchers. For a heavy vehicle weighing more than 15 tons, about $1 / 3$ of the life cycle cost comes from the cost of fuel [1]. As a special vehicle, mining truck weighting around 50 tons, the average fuel consumption is around $100 \mathrm{~L} / 100 \mathrm{~km}$. For this type of vehicle, the gear shifting strategy improving fuel efficiency in every trip has good benefit in the whole life cycle.

The drive cycle of mining truck is often regulated in advance, which locates between source area and storage area. It leads to collecting elevation and slope data easily. With known road data, it is available to use dynamic programming approach to optimize the gear shifting strategy to reduce the fuel consumption and trip time. As a numerical method for solving multistage decision-making problems, dynamic programming has been applied to optimize fuel and electricity costs associated with two supervisory control strategies for a series of plug-in hybrid electric vehicle and control strategy for heavy hybrid electric truck $[2,3]$. Besides, it is proposed for design of the optimal gear shift strategy to study quantitatively an optimal trade-off between the fuel economy and the drivability [4]. At present, some researchers have developed economical gear shifting strategy applying for heavy duty truck. The problem that which kind of speed profile will minimize fuel consumption of a land vehicle is stated. Based on different guide way characteristics, the optimal speed profile is analyzed for minimizing fuel consumption [5]. Lattemann and his colleagues used predictive cruise control allowing the vehicle speed to vary around the cruise control by setting speed within a defined speed band in an effort to reduce fuel consumption for trucks [6]. The efficiency of engine, the powertrain system, and the pump are considered and set up the optimal economy gear shifting strategy for construction vehicles $[7,8]$. Shi et al. used a modified recursive least square method to estimate the vehicle mass and generalized slope and made a self-adaptive gear shifting strategy of uphill and downhill 
slopes without considering fuel consumption [9]. For costing lots of fuel consumption, it should be considered into gear shifting strategy. The method of modeling and calculating fuel consumption for heavy-duty vehicle was illustrated, and it had been verified by experiments [10]. Therefore, it is plausible to calculate the fuel consumption based on the accurate powertrain system model and real road profile. For optimization, economical strategy for a heavy truck is conducted by finding how to drive a truck over various road topographies. While the results show that the optimal solution is to keep constant speed for level road and in small gradients [11], Delgado et al. got the results which show that the use of average velocity and average positive acceleration was suitable for the translation of fuel consumption [12].

In this work, an optimal control algorithm based on dynamic programming is formulated to find gear shifting strategy for a mining truck weighting 50 tons. Comparing different step lengths, the proper length had been found with considering accuracy and enumeration load. With a traditional powertrain model and known road profile ahead, we minimized trip time and fuel consumption in different initial states on simple road profile separately. The results show there is a trade-off between trip time and fuel consumption in all of cases and when it achieves the highest fuel economy with sacrificing the trip time. Taking into account all characteristics of powerful strategy and economical strategy, the trip time becomes a constraint instead of a part of objective function. The optimal gear shifting strategy presents that it spends less fuel consumption than powerful strategy and takes fewer time than economical strategy. The optimal algorithm could be applied to find an economical gear shifting strategy with desired average speed. In addition, two special road profiles are substituted for simple road and the optimal results accord with the results derived from simple road profile. Combing a two-dimensional dynamic programming algorithm with weighted cost function and known route information will be discussed and compared in trip time and fuel consumption.

\section{Modeling for Mining Truck Powertrain System}

2.1. Powertrain System Configuration and Dynamics Analysis. Powertrain system of mining truck comprises an engine, an automatic transmission, a drive shaft, a retarder, and a wheelside reducer. The power produced by engine transfers from engine to wheel through transmission system to drive the vehicle [13]. Figure 1 shows the configuration and torque pass line of driveline for a 50-ton mining truck. Table 1 shows the main parameter of the truck.

The truck equips one of the M11 series diesel engines produced by Cummins, and the output power is related to the mass of fuel in every stroke cycle $u_{f}$ and engine angle speed $\omega_{e}$. Based on experimental data, the output torque can be expressed by a polynomial as follows:

$$
T_{e}\left(\omega_{e}, u_{f}\right)=a_{1} \omega_{e}+a_{2} u_{f}+a_{3}
$$

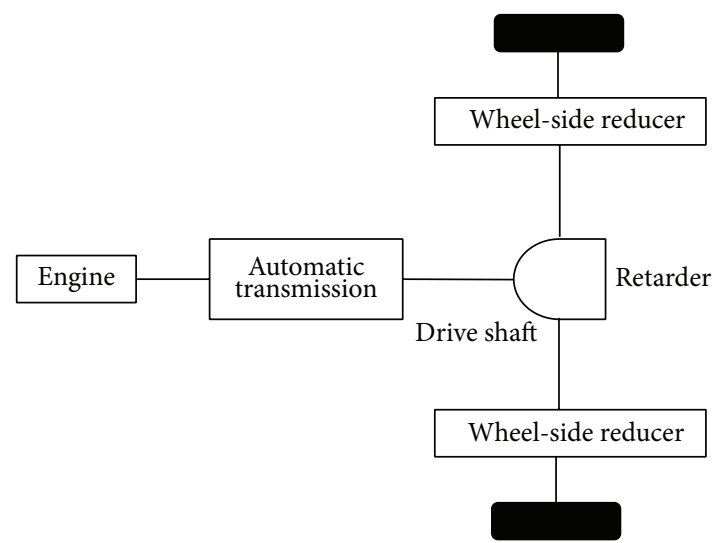

FIGURE 1: The scheme of the powertrain system for a 50-ton mining truck.

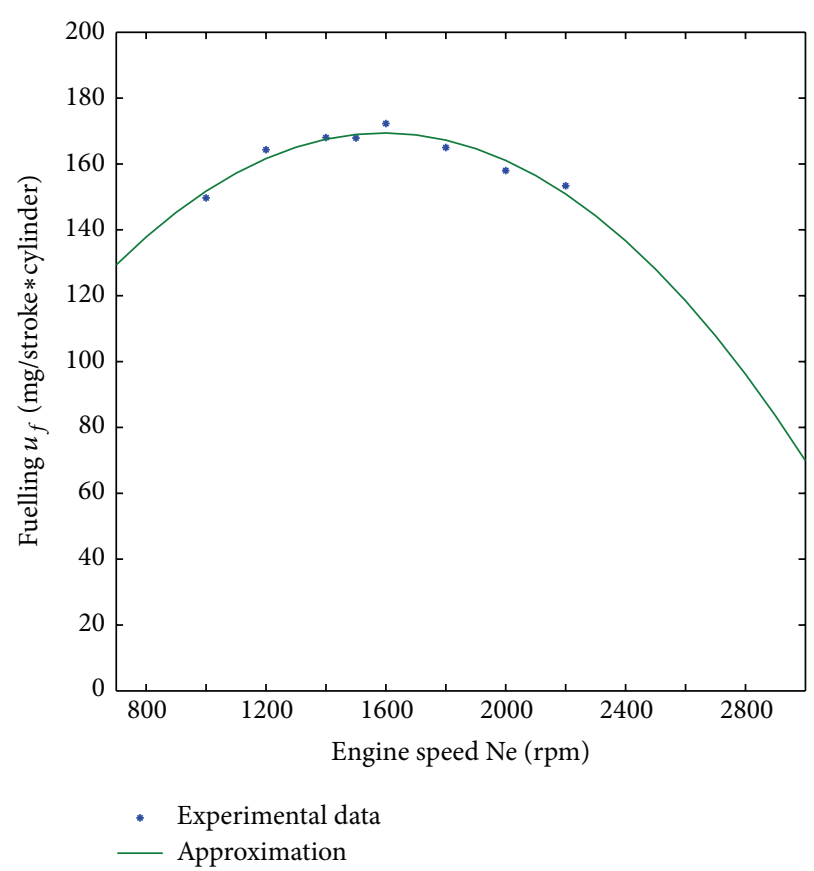

FIgURE 2: Fueling bounds and experimental data.

where the maximum value of fueling depends on a quadratic polynomial of the engine angle speed, like

$$
u_{f, \max }=a_{4} \omega_{e}^{2}+a_{5} \omega_{e}+a_{6} .
$$

In the above equation, the coefficients from $a_{1}$ to $a_{6}$ are derived from the experimental data of this engine. From Figure 2, it shows that the fueling bounds appear to be well approximated by using the polynomial (2).

Newton's second law of the motion gives the relation between the engine acceleration of angle speed $\dot{\omega}_{e}$, the inertia of the rotating parts $J_{e}$, the output torque of engine $T_{e}$, the input torque $T_{t}$ to converter, and loss torque $T_{\text {fric,e }}$. Consider

$$
J_{e} \dot{\omega}_{e}=T_{e}-T_{\text {fric }, e}-T_{t}
$$


TABLE 1: Main parameters of the vehicle.

\begin{tabular}{lc}
\hline Item & Description or quantity \\
\hline Engine & Diesel; displacement: 8.9 L; maximum \\
Transmission & power: $242 \mathrm{kw}$; maximum torque: $1424 \mathrm{Nm}$ \\
Vehicle mass & Five-speed AT; \\
\hline
\end{tabular}

TABLE 2: Resistance.

\begin{tabular}{lcc}
\hline Symbol & Explanation & Equation \\
\hline$F_{\text {wind }}$ & Air drag & $\frac{1}{2} c_{w} A_{a} \rho_{a} v^{2}$ \\
$F_{R}$ & Rolling resistance & $m g c_{r} \cos \alpha$ \\
$F_{\text {gra }}$ & The gravitational force & $m g \sin \alpha$ \\
\hline
\end{tabular}

When a gear is engaged, the torque at wheel $T_{w}$ can be determined by the lumped rotating inertia $J_{l}$, the gear ratio $i_{g}$, and the lumped reduction ratio from retarder and wheelside reducer. Ignoring the brake torque, denote $T_{w}$ and $T_{t}$ as the following equations:

$$
\begin{gathered}
T_{w}=i i_{g} \eta T_{t}, \\
J_{l} \dot{\omega}_{w}=T_{w}-T_{L}-F_{L} r_{w},
\end{gathered}
$$

where $\eta$ is the transmission efficiency of the driveline system and $\dot{\omega}_{w}, T_{L}, F_{L}$, and $r_{w}$ represent the angular acceleration, braking torque, friction, and radius of wheel, respectively.

Based on the longitudinal dynamics of vehicle, the friction of wheel can be described by Newton's second law. The equation shows the following, where $m$ is the mass of vehicle and $v$ is velocity of vehicle. In the longitudinal direction, the main resisting forces are considered to be air drag, rolling resistance, and gravitational force, which are illustrated in Table 2. Consider

$$
F_{L}=m \frac{d v}{d t}+F_{\text {wind }}+F_{R}+F_{\text {gra }} .
$$

Combining (1) to (5), the acceleration of vehicle can be represented by parameters that are mentioned in this section [14]. Consider

$$
\begin{aligned}
\frac{d v}{d t}\left(v, u_{f}, \alpha\right)= & \frac{r_{w}}{J_{l}+m r_{w}^{2}+\eta i^{2} i_{g}^{2} J_{e}} \\
& \cdot\left(i i_{g} \eta T_{e}\left(v, u_{f}\right)\right. \\
& \left.\quad-r_{w}\left(F_{\text {wind }}(v)+F_{R}(\alpha)+F_{\text {gra }}(\alpha)\right)\right) .
\end{aligned}
$$

2.2. Fuel Consumption. The advanced internal combustion engine produces power and emission from fuel and air in every stroke. The fuel consumption $m_{f}(\mathrm{~g} / \mathrm{s})$ is identified depending on fueling $u_{f}$ (g/stroke $*$ cylinder) and engine speed $\omega_{e}(\mathrm{rad} / \mathrm{s})[15]$. Consider

$$
\frac{d m_{f}}{d t}\left(\omega_{e}, u_{f}\right)=\frac{n_{\mathrm{cyl}}}{2 \pi n_{r}} \omega_{e} u_{f}=\frac{n_{\mathrm{cyl}} i i_{g}}{2 \pi n_{r} r_{w}} v u_{f},
$$

where $n_{\text {cyl }}$ is the number of cylinders and $n_{r}$ is the crank rotation number in every stroke.

2.3. Reformulation Model by Displacement. For optimization by numerical method, the model should be transformed from being parameterized by time to being parameterized by position. Since the states including velocity and fuel consumption are discrete in regard to time, they need to be represented by position. Assuming a short distance $p$, it is the function of time $t$ and the function of displacements $[16,17]$. Then, $p$ can be represented as follows:

$$
\frac{d p}{d s}=\frac{d p}{d t} \frac{d t}{d s}=\frac{d p}{d t} \frac{1}{v} \Longrightarrow \Delta t=\frac{\Delta p}{v}
$$

When the speed $v>0$, the short distance is assumed to be $p_{k}$. Therefore, (6) and (7) will be transferred to the next two equations:

$$
\begin{gathered}
v_{k+1}=v_{k}+\Delta t_{k} \cdot \frac{d v}{d t}=v_{k}+\frac{p_{k}}{v_{k}} \cdot \frac{d v}{d t} \\
m_{f, k+1}=m_{f, k}+\Delta t_{k} \cdot \frac{d m_{f}}{d t}=m_{f, k}+\frac{p_{k}}{v_{k}} \cdot \frac{d m_{f}}{d t} .
\end{gathered}
$$

In this problem, the velocity of vehicle, fuel consumption, and gear number in current state can be described by their value of last state. The state vector is assumed to be $x=\left[v, g_{k}\right]^{T}$. By ignoring the braking torque, the control trajectory is the gear shifting state $u=\left[u_{g}\right]^{T}$.

\section{Optimizing Gear Shifting Strategy by Dynamic Programming}

Mining truck is different from passenger car in several aspects, such as driving condition. The trajectory of off-road vehicle is usually fixed from mining area to intermediate of transport. This route can be divided into small steps and the distance of each part is equal to $p_{k}$. The gear number for the next step is decided by dynamic programming algorithm to minimize cost function for the next step. Following the same way, the gear shifting strategy will be acquired for the whole route.

3.1. Constraints of State. The roads of mining truck may decline sharply which results in the actual speed just achieving $80 \%$ of the maximum speed. The speed should be less than the maximum speed of current gear $\left(v_{g, \max }\right)$ and larger than the minimum speed of current gear $\left(v_{g, \text { min }}\right)$ [18]. For different gear, the range of speed is shown as follows:

$$
0<v_{\min } \leq v(g) \leq 0.8 v_{\max }, \quad 0<v_{g, \min } \leq v(g) \leq v_{g, \max } .
$$

There are five gears for the automatic transmission equipping in mining truck, and the gear number should be continuously assuming no gear skipping. Therefore, gear 
number needs to satisfy the following constraints, when the current gear is $g_{k}$ and the next gear is $g_{k+1}$. Consider

$$
g_{k+1} \in \begin{cases}(1,2), & \text { if } g_{k}=1, \\ (4,5), & \text { if } g_{k}=5 \\ \left(g_{k}, g_{k+1}, g_{k+2}\right), & \text { otherwise. }\end{cases}
$$

Because of the fuel consumption calculated by real engine speed and torque, there are no other constraints.

3.2. Constraints of Control. The transmission control unit (TCU) sends gear shifting signals to transmission. The range of control policy also needs to be considered with the current gear number. When the gear is the highest gear, it is impossible to upshift any more. While the gear is the lowest gear, it cannot continue to downshift. Otherwise, the control policy can be any plausible value of $-1,0$, and 1 . Consider

$$
u_{g, k} \in \begin{cases}(0,1), & \text { if } g_{k}=1, \\ (-1,0), & \text { if } g_{k}=5 \\ (-1,0,1), & \text { otherwise. }\end{cases}
$$

3.3. Objective Function. Considering fuel consumption with ignoring trip time, a truck will have a powerful performance. Therefore, the objective function included not only fuel consumption costing on a known route but also trip time. Moreover, penalty coefficients in the cost function are used to adjust a trade-off between powerful and economical performances of vehicle. The cost function taking into account both trip time and fuel consumption is shown as follows:

$$
\begin{array}{r}
J=\xi_{k}\left(x_{k}, u_{k}\right)=\sum_{k=0}^{N-1} \alpha \cdot m_{f, k}\left(x_{k}\right)+\sum_{k=0}^{N-1} \beta \cdot t_{k}\left(x_{k}\right) \\
k=0,1,2, \ldots, N-1,
\end{array}
$$

where $\alpha$ and $\beta$ are the penalty coefficients for fuel consumption and trip time, respectively, and $N$ is the number of steps dividing the whole journey.

3.4. Application of the Dynamic Programming Algorithm. For a given system, dynamic programming can be used to find the optimal control input that minimizes a chosen cost function. However, all dynamic programming algorithms are based on decision processes. It means that a dynamic system with continuous inputs and states has to be approximated by a discrete-value system. There are several issues need to be considered for implementing the algorithm, including grid selection, interpolation, and assuming parameters of algorithm. For dynamic programming approach, the control variable needs to be discrete firstly. Plausible values of gear control $u=\left[u_{g}\right]^{T}$ are given by the constraint of gear number. For system state $x=\left[v, g_{k}\right]^{T}$ in stage $k$, all plausible next states can be described by (14). When the state is shown as follows,
TABLE 3: Parameters for dynamic programming.

\begin{tabular}{lcc}
\hline Parameter & Explanation & Value \\
\hline$p_{k}$ & Step length & $5 \mathrm{~m}$ \\
$N$ & Number of step & 20 \\
$p_{k} \cdot N$ & Distance & $100 \mathrm{~m}$ \\
$\alpha$ & Coefficient of economical performance & 1 or 0 \\
$\beta$ & Coefficient of powerful performance & 1 or 0 \\
\hline
\end{tabular}

the cost-to-go function is written as (15), where $x_{k+1}^{n}$ are state vectors at stage $k+1$. Consider

$$
\begin{gathered}
x_{k+1}=\left[\begin{array}{l}
v_{k+1} \\
g_{k+1}
\end{array}\right]=\left[\begin{array}{l}
v_{k} \\
g_{k}
\end{array}\right]+\left[\begin{array}{l}
0 \\
1
\end{array}\right] \cdot\left[u_{g}\right]+\left[\begin{array}{c}
\frac{d v}{d s} \\
0
\end{array}\right] \cdot[d s], \\
\widehat{J}_{k+1}\left(x_{k+1}\right)=\sum_{n=m}^{m+1} \psi^{n} J\left(x_{k+1}^{n}\right) .
\end{gathered}
$$

Based on the cost-to-go function and state values, the algorithm is illustrated as the following procedures of dynamic programming [19]:

(i) find the $J_{N}(f(x, u))=\min \left\{J\left(x_{k+1}^{n}\right)\right\}$;

(ii) let $k=N-1$;

(iii) let $J_{k}(f(x, u))=\min _{u \in U}\left\{\xi_{k}(x, u)+J_{k+1}(f(x, u))\right\}$;

(iv) repeat the last step for $k=N-a, a=2,3, \ldots, N$;

(v) the minimum cost based on the optimal control is $J_{0}$, where the controls are coming from the initial state.

To find the optimal gear shifting schedule for making mining truck powerful and economical, (13) is used as the cost function with considering constraints of states and controls. The states are discrete into a matrix whose size is $9 \times 5$. Because velocity is continuous and valuable, the interval of discretization is assumed to be $5 \mathrm{~km} / \mathrm{h}$. Allowable controls are applied in every step, and the optimal control is recorded in every step, which makes cost become the minimum one. Repeating mentioned process, the minimum cost will be found when the step goes to the first step. It means that the controls are the best gear shifting strategy combining powerful and economical performance for mining truck. The parameters of approach are presented in Table 3.

\section{Discussion}

The problem optimizing gear shifting strategy to make vehicle performance powerful and economical will be transferred to a general problem that is searching an array control policy to minimize the cost function with specific constraints. In this section, the results are described with adjusting different step lengths, initial states, and coefficients of powerful and economical performance. How those mentioned parameters influence results is conducted in this section.

4.1. Optimizing Gear Shifting Strategy in Different Step Lengths. Assume the route ahead of mining truck is $100 \mathrm{~m}$ straight without any slope. The powerful coefficient is set to 


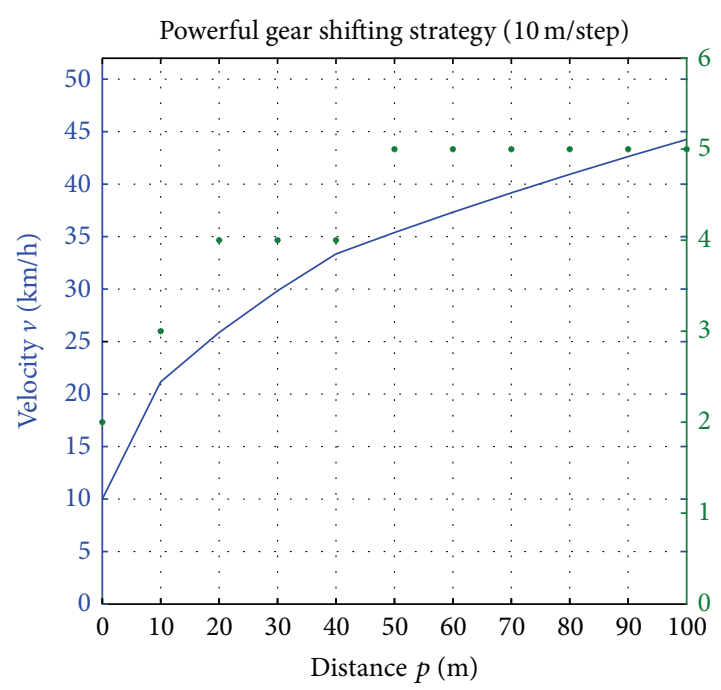

(a)

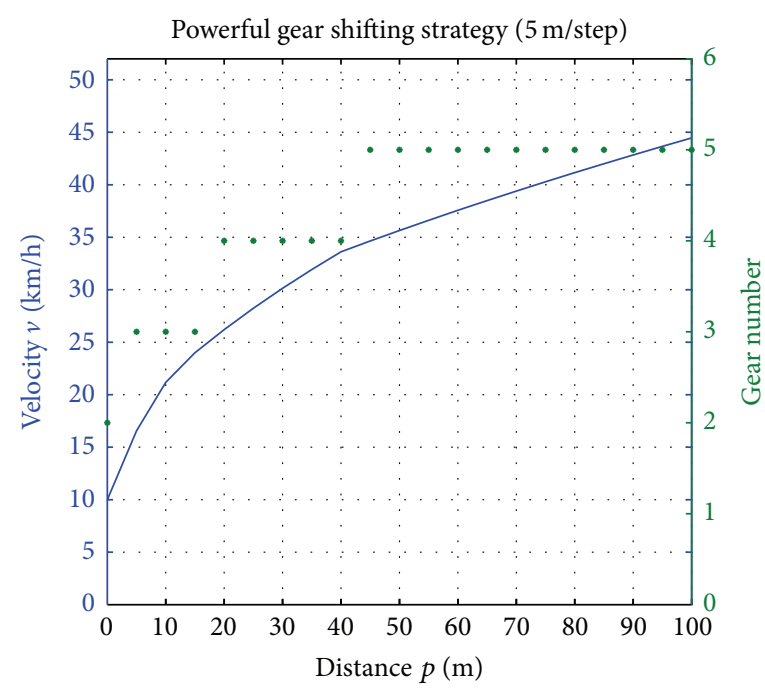

(b)

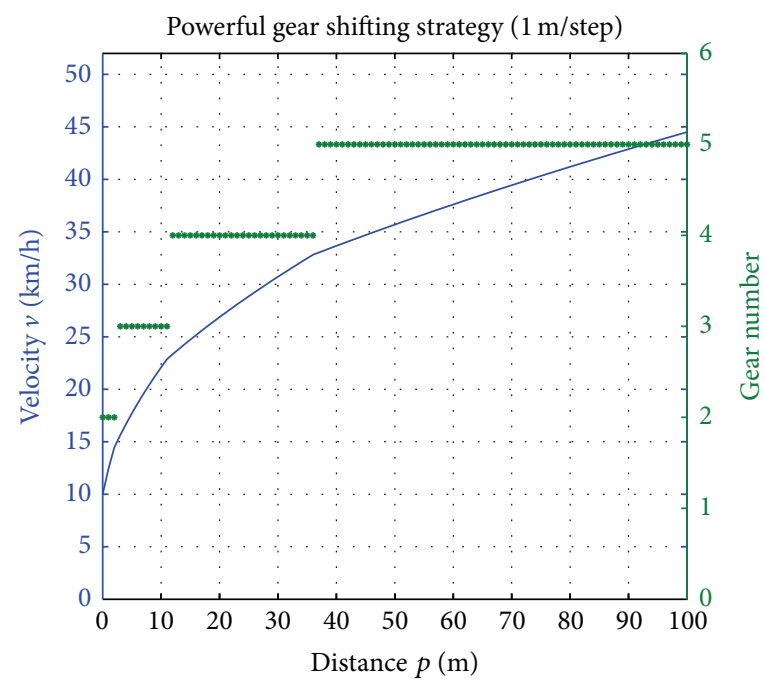

(c)

FIGURE 3: The performance of vehicle in different step lengths.

be 1 while economical coefficient is set to be 0 . It means that the objective function just considered trip time and the optimal results are the powerful gear shifting strategy. The simulations in same initial state $(10 \mathrm{~km} / \mathrm{h}, 2$ nd gear) are conducted with different step lengths, such as $10 \mathrm{~m}, 5 \mathrm{~m}$, and $1 \mathrm{~m}$. Comparing the results in different step lengths, the optimal gear shifting strategy based on minimizing trip time can be seen in Figure 3.

The final states of different step lengths are almost the same, while the trip time of those conditions almost spends the same time: $11.48 \mathrm{~s}$ for $10 \mathrm{~m} / \mathrm{step}, 11.41 \mathrm{~s}$ for $5 \mathrm{~m} / \mathrm{step}$, and $11.21 \mathrm{~s}$ for $1 \mathrm{~m} / \mathrm{step}$. The moments achieving the fifth gear for different conditions are different. For step length of $10 \mathrm{~m}$, the gear increases by the fifth gear after the vehicle runs to $50 \mathrm{~m}$, while the distances are $40 \mathrm{~m}$ and $37 \mathrm{~m}$ for $5 \mathrm{~m} / \mathrm{step}$ and $1 \mathrm{~m} / \mathrm{step}$, respectively. Therefore, the optimal control is influenced by step length in the same horizon. However, step length is not as small as possible for a numerical approach.
The smaller step length is applied, the more times iteration is used. It results in increasing the computational complexity. For actual problem, the step length should consider the response performance of vehicle system. If the frequency of gear shifting exceeds the intrinsic system value, it deteriorates the comfort performance and components abrasion. As can be seen from Figure 3, the results of $5 \mathrm{~m} / \mathrm{step}$ state the main performance index of vehicle gear shifting without calculation burden and this length is adapted in the following work.

The computational complexity is determined by the dimensions and the number of quantization levels used for the state and control spaces. The step length determines the minimum interval for gear shifting [20]. In different step lengths, the required computation time becomes

$$
T=z N N_{x} N_{u},
$$



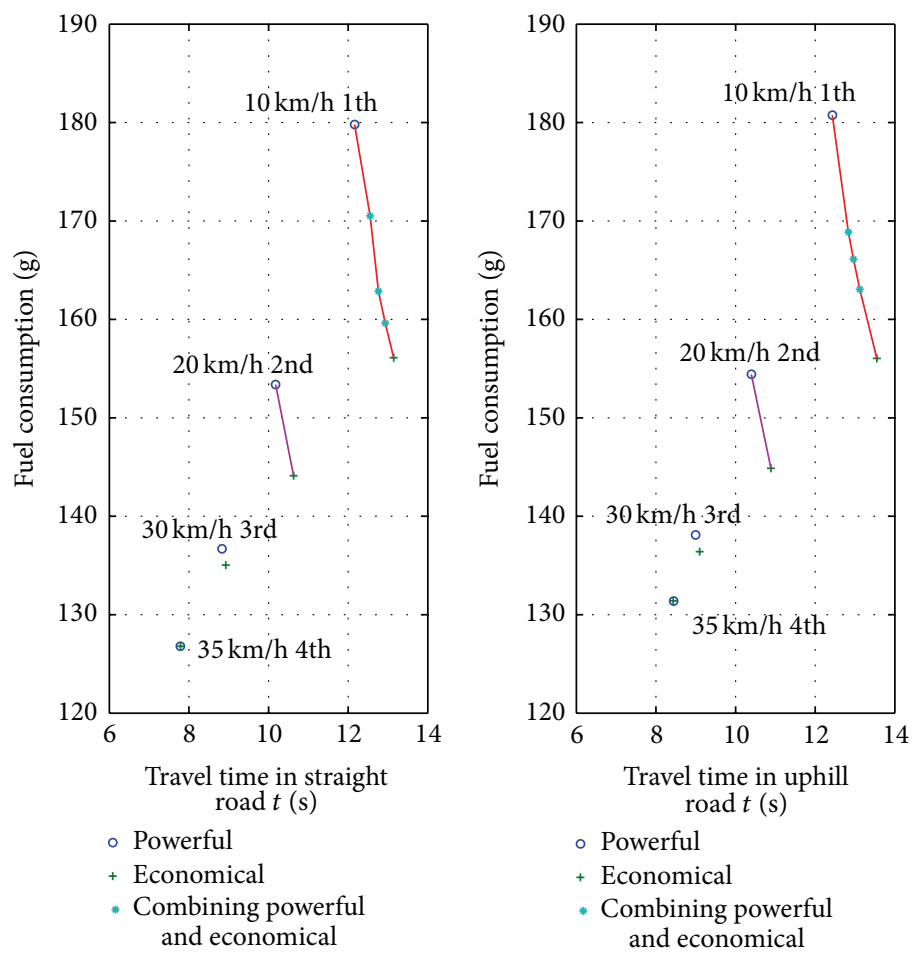

FIgURE 4: The trade-off between fuel consumption and trip time in different conditions.

where $z$ is a constant and $N_{x}$ and $N_{u}$ are the total number of state grid points and discrete controls, respectively. The constant is mainly dependent on the capacity and speed of the available computer hardware.

\subsection{The Relationship between Fuel Consumption and Trip}

Time. The best shifting schedule is to take the lowest fuel consumption and the shortest trip time in the same time. However, there is a coupling relationship between trip time and fuel consumption. According to the conservation of energy, it takes more fuel consumption to obtain more power when the trip time is too short, but when we need to save the fuel, the trip time should be increased to produce the same amount of power. Therefore, how much of the fuel consumption increases when reducing the trip time is the key to choose which kind of shifting schedule for this system.

To solve this problem, the trip time is changed to become a constraint by modifying the previous model of dynamic programming. The result shows that the optimized shifting schedule balances the power and the economy. Using the $10 \mathrm{~km} / \mathrm{h}$ at the first gear as the initial state, the results are showed in Figure 4. The quantitative relationship between trip time and fuel consumption is set up, which has been improved and is acceptable. In Figure 4 the left figure shows the results in $100 \mathrm{~m}$ straight road, and right one states the results in $100 \mathrm{~m}$ uphill road with a 2.5 (rad) slope.

Choosing four kinds of states as initial states, the model is conducted in straight road and uphill road, respectively. As showed in Figure 4, when initial state is $35 \mathrm{~km} / \mathrm{h}$ at the fourth gear, the results are in the area of high speed with low
TABLE 4: Main parameters on convex road.

\begin{tabular}{lcc}
\hline Specific strategy & Trip time/s & $\begin{array}{c}\text { Fuel } \\
\text { consumption/L }\end{array}$ \\
\hline $\begin{array}{l}\text { Economical gear shifting } \\
\text { strategy }\end{array}$ & 62.15 & 0.7522 \\
$\begin{array}{l}\text { Powerful gear shifting } \\
\text { strategy }\end{array}$ & 53.23 & 0.7527 \\
\hline
\end{tabular}

fuel consumption, which indicates that the result of powerful shifting schedule is the same as that economical shifting schedule. The gear shifting schedule by using the dynamic programming is beneficial for finding optimal strategy with fixed real road profile.

\subsection{Comparison of Performances in Different Road Profiles}

4.3.1. For Convex Road Surface. Examples of convex road are seen in Figure 5, which is $340 \mathrm{~m}$. It gives the variation of trip time, fuel consumption, velocity, and gear versus the displacement. The blue stars represent the gear shifting schedule for minimizing fuel consumption. Gear increases to the fourth gear before $100 \mathrm{~m}$ while gear in optimizing trip time case keeps on low gear at that moment. The reason is that vehicle at low gear is easy to achieve high acceleration. The trip time taking by minimizing fuel consumption case is longer than another case, and velocity has achieved the same value at the end of route.

The specific value of trip time and fuel consumption is shown in Table 4, where the data in the row of economical 

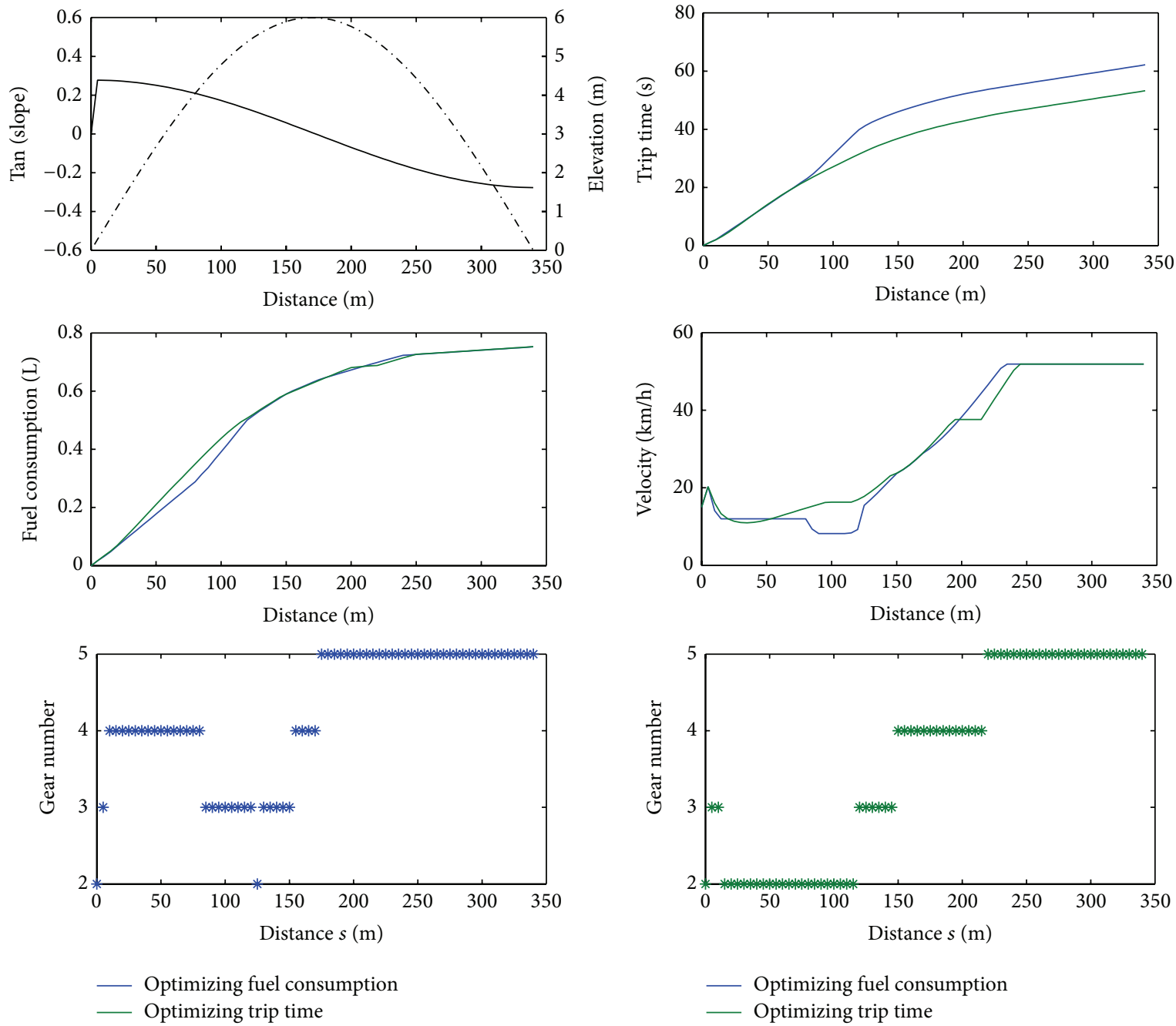

FIGURE 5: Vehicle performances on convex road.

gear shifting strategy means the results by minimizing fuel consumption. Simulations on $340 \mathrm{~m}$ convex route show that the trip time for a mining truck was reduced by $14.3 \%$ with an insignificant change in trip time with powerful gear shifting strategy. Although there are few differences for trip time and fuel consumption, it will become a large value when route extends to hundreds of miles.

4.3.2. For Concave Road Surface. In Figure 6 an example of concave road is shown. Simulations on the entire rote are made with varying horizon lengths. The gear shifting strategies in different cost functions have similar trends before $300 \mathrm{~m}$, while gear is decreased from fifth to third gear at the end of route when minimizing trip time. It leads to the fact that the velocity for optimizing fuel consumption is less than the velocity in another case. To see results clearly, the specific values were shown in Table 5.

Based on all of the results, the gear shifting strategy with different cost functions has correct response for the minimized parameter, and it validates that the algorithm of dynamic programming is reasonable. It can be applied for the
TABLE 5: Main parameters on concave road.

\begin{tabular}{lcc}
\hline Specific strategy & Trip time/s & $\begin{array}{c}\text { Fuel } \\
\text { consumption/L }\end{array}$ \\
\hline $\begin{array}{l}\text { Economical gear shifting } \\
\text { strategy }\end{array}$ & 30.56 & 0.3883 \\
$\begin{array}{l}\text { Powerful gear shifting } \\
\text { strategy }\end{array}$ & 29.58 & 0.3998 \\
\hline
\end{tabular}

real road profile for looking for the economical gear shifting strategy and powerful gear shifting strategy.

\section{Conclusion}

The paper established a shifting schedule based on the dynamic programming (DP) theory for off-road vehicle, with making fuel consumption and trip time as the objective function and gear changing as the controlling variable. Comparing and selecting the appropriate step length, it ensures the simulation to be accurate and efficient. 

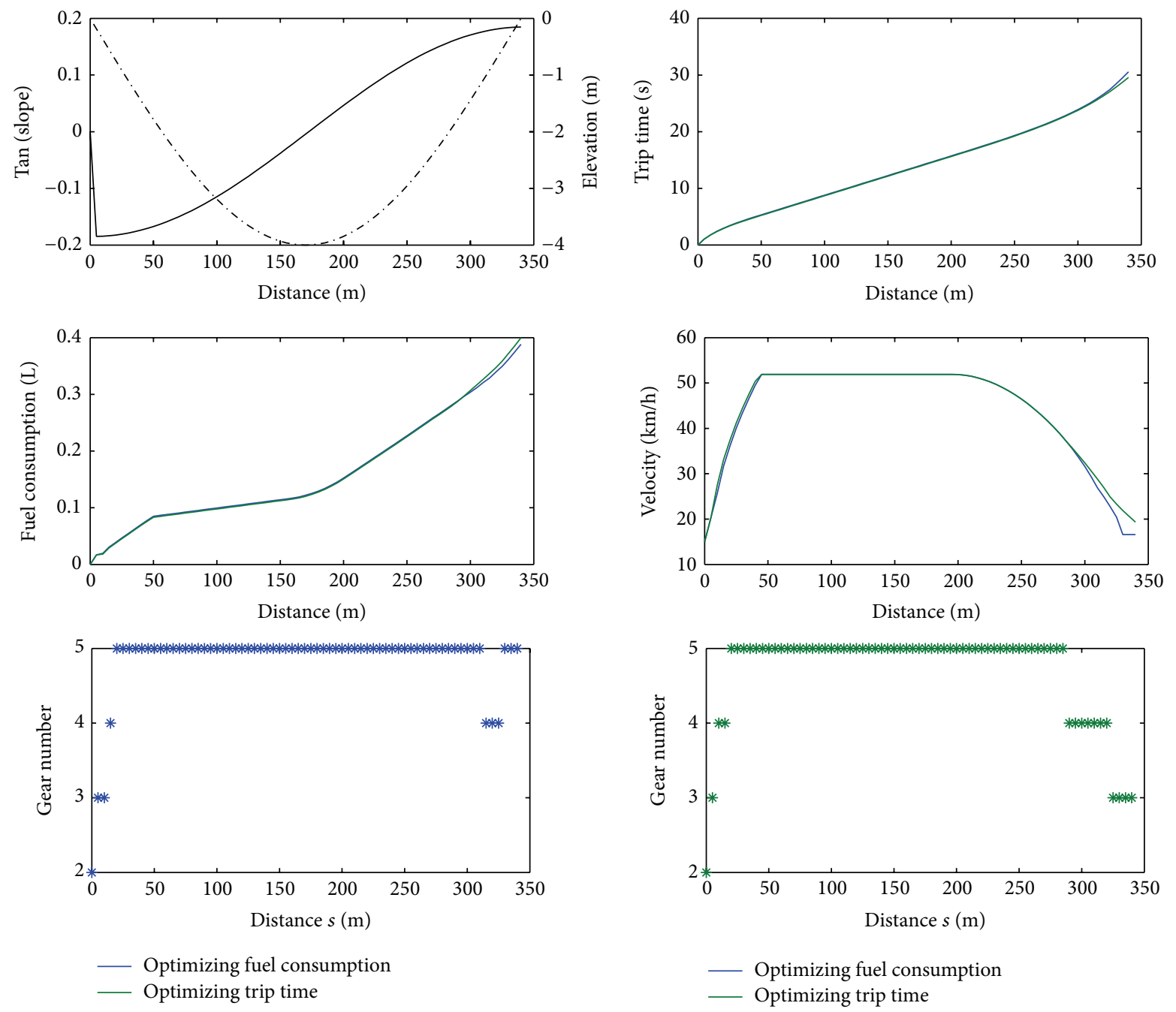

FIGURE 6: Vehicle performances on concave road.

Adjusting the penalty coefficients in the objective function is to optimize the powerful and economical strategy. The trip time is considered to be a constraint when making economical shifting strategy that balances the power and economy for mining truck. For the actual condition, the powerful shifting schedule has contributed to get the relationship between increment of the fuel consumption and decrement of the trip time. For the future work, the road profile should be alerted to the actual road with sorted of conditions and desired velocity penalty function can be added into objective function. Based on real road profile, the optimization will be conducted for minimizing fuel consumption for mining truck by using this method. The optimal control strategy derived from dynamic programming can be applied to the transmission control unit for saving fuel and time.

\section{Conflict of Interests}

The authors declare that there is no conflict of interests regarding the publication of this paper.

\section{Acknowledgments}

The authors would like to gratefully acknowledge the China Scholarship Council for their support of this research. The authors also like to thank Professor Nasser Lashgarian Azad from the University of Waterloo for his good advises.

\section{References}

[1] E. Hellström, M. Ivarsson, J. Åslund, and L. Nielsen, "Lookahead control for heavy trucks to minimize trip time and fuel consumption," Control Engineering Practice, vol. 17, no. 2, pp. 245-254, 2009.

[2] Y. Zou, D.-G. Li, and X.-S. Hu, "Optimal sizing and control strategy design for heavy hybrid electric truck," Mathematical Problems in Engineering, vol. 2012, Article ID 404073, 15 pages, 2012.

[3] R. M. Patil, Z. Filipi, and H. K. Fathy, " Comparison of supervisory control strategies for series plug-in hybrid electric vehicle powertrains through dynamic programming," IEEE 
Transactions on Control Systems Technology, vol. 22, no. 2, pp. 502-509, 2013.

[4] V. D. Ngo, J. C. Navarrete, T. Hofman, M. Steinbuch, and A. Serrarens, "Optimal gear shift strategies for fuel economy and driveability," Proceedings of the Institution of Mechanical Engineers D: Journal of Automobile Engineering, vol. 227, no. 10, pp. 1398-1413, 2013.

[5] D. J. Chang and E. K. Morlok, "Vehicle speed profiles to minimize work and fuel consumption," Journal of Transportation Engineering, vol. 131, no. 3, pp. 173-182, 2005.

[6] F. Lattemann, K. Neiss, S. Terwen, and T. Connolly, "The predictive cruise control-a system to reduce fuel consumption of heavy duty trucks," SAE Paper 2004-01-2616.

[7] G. J. Cui, Study on Three-Parameter Optical Shift Schedule and Control Method of Construction Vehicle, Jilin University, Jilin, China, 2009.

[8] Z. Miao, Research on saving energy shift schedule with fourparameter and the control system of construction vehicle, Jilin University, Jilin, China, 2006.

[9] J. Shi, T. Lu, X. Li, and J. Zhang, "Self-adaptive slope gearshift strategy for automatic transmission vehicles," Transactions of the Chinese Society of Agricultural Machinery, vol. 42, no. 4, pp. 1-7, 2011.

[10] T. Sandberg, Heavy Truck Modeling for Fuel Consumption Simulations and Measurements, Linköping Studies in Science and Technology, Linköping, Sweden, 2001.

[11] A. Fröberg, E. Hellström, and L. Nielsen, "Explicit fuel optimal speed profiles for heavy trucks on a set of topographic road profiles," SAE Paper 2006-01-1071, 2006.

[12] O. F. Delgado, N. N. Clark, and G. J. Thompson, "Heavy duty truck fuel consumption prediction based on driving cycle properties," International Journal of Sustainable Transportation, vol. 6, no. 6, pp. 338-361, 2012.

[13] A. Fröberg and L. Nielsen, "Efficient drive cycle simulation," IEEE Transactions on Vehicular Technology, vol. 57, no. 3, pp. 1442-1453, 2008.

[14] U. Kiencke and L. Nielsen, Automotive Control System: For Engine, Driveline, and Vehicle, Springer, Berlin, Germany, 2nd edition, 2005.

[15] E. Hellström, A. Fröberg, and L. Nielsen, "A real-time fueloptimal cruise controller for heavy trucks using road topography information," SAE Paper 2006-01-0008.

[16] M. Ivarsson, J. Åslund, and L. Nielsen, "Look-ahead controlconsequences of a non-linear fuel map on truck fuel consumption," Proceedings of the Institution of Mechanical Engineers D: Journal of Automobile Engineering, vol. 223, no. 10, pp. 12231238, 2009.

[17] R. Franke, P. Terwiesch, and M. Meyer, "An algorithm for the optimal control of the driving of trains," in Proceedings of the 39th IEEE Confernce on Decision and Control, vol. 3, pp. 21232128, Sydney, Australia, December 2000.

[18] B. Saerens, J. Vandersteen, T. Persoons, J. Swevers, M. Diehl, and E. V. Bulck, "Minimization of the fuel consumption of a gasoline engine using dynamic optimization," Applied Energy, vol. 86, no. 9, pp. 1582-1588, 2009.

[19] D. E. Kirk, Optimal Control Theory: An Introduction, New York, NY, USA, Dover, 2004.
[20] E. Hellström, Look-Ahead Control of Heavy Trucks Utilizing Road Topography, Linköping University, Linköping, Sweden, 2007. 


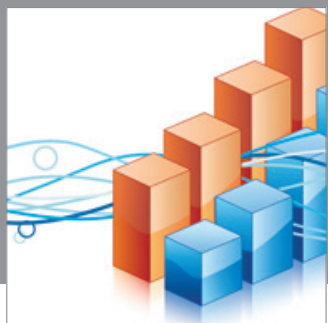

Advances in

Operations Research

mansans

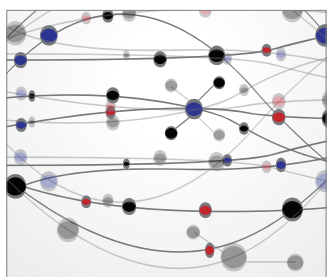

The Scientific World Journal
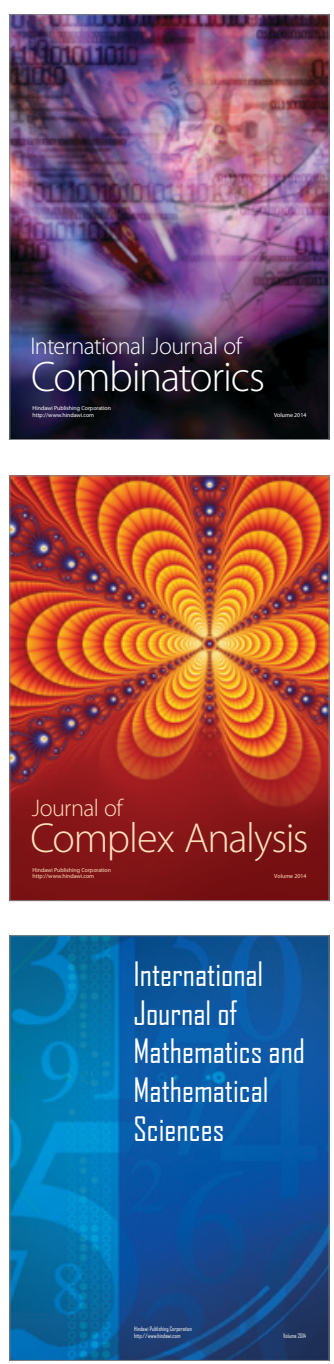
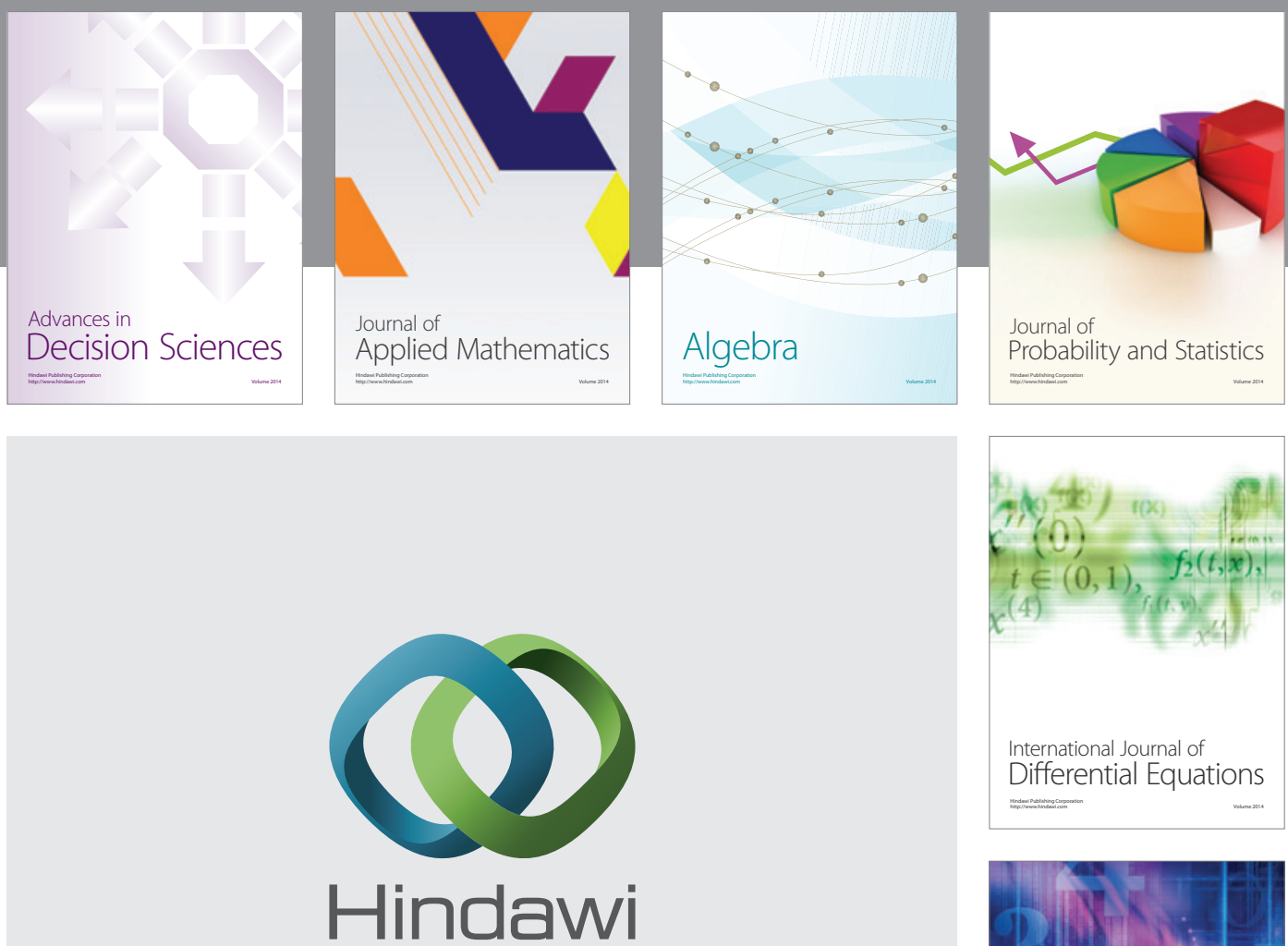

Submit your manuscripts at http://www.hindawi.com
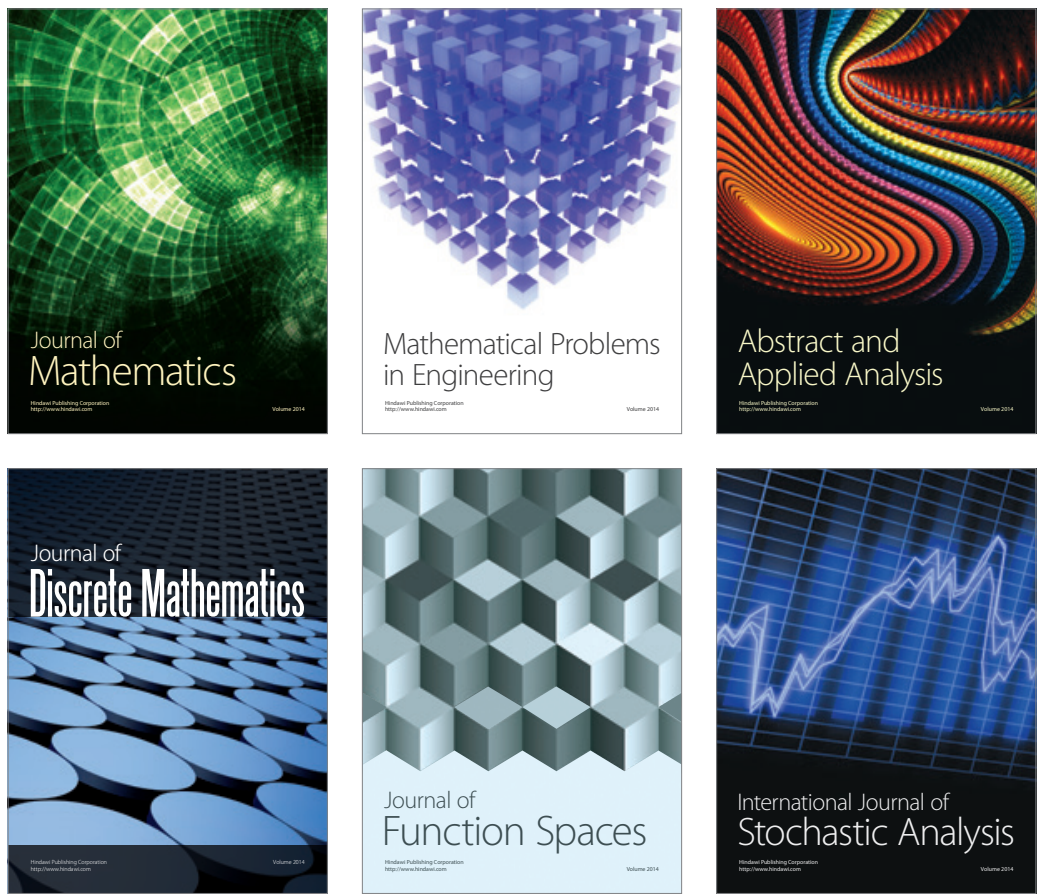

Journal of

Function Spaces

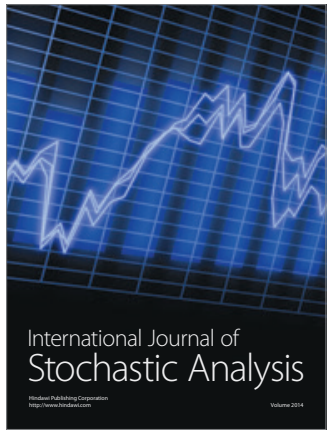

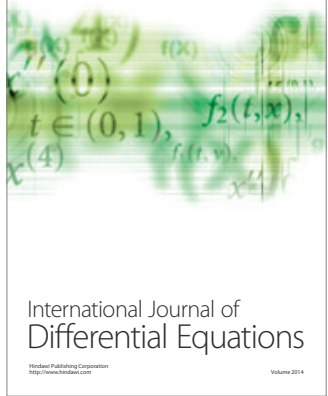
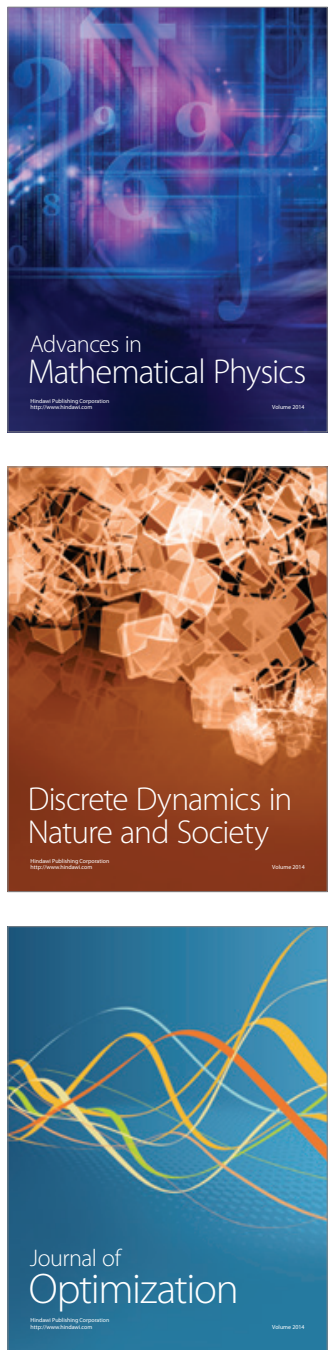